\title{
Cognitive assessment instruments in Parkinson's disease patients undergoing deep brain stimulation
}

\author{
Aline Juliane Romann ${ }^{1}$, Silvia Dornelles² ${ }^{2}$ Nicole de Liz Maineri³ \\ Carlos Roberto de Mello Rieder ${ }^{4}$, Maira Rozenfeld Olchik ${ }^{5}$
}

\begin{abstract}
Deep Brain Stimulation (DBS) is a widely used surgical technique in individuals with Parkinson's disease (PD) that can lead to significant reductions in motor symptoms. Objectives: To determine, from publications, the most commonly used instruments for cognitive evaluation of individuals with PD undergoing DBS. Methods: A systematic review of the databases: PubMed, Medline, EBECS, Scielo and LILACS was conducted, using the descriptors "Deep Brain Stimulation", "Verbal Fluency", "Parkinson Disease", "Executive Function", "Cognition" and "Cognitive Assessment" in combination. Results: The Verbal Fluency test was found to be the most used instrument for this investigation in the studies, followed by the Boston Naming Test. References to the Stroop Test, Trail Making Test, and Rey's Auditory Verbal Learning Test were also found. Conclusions: The validation of instruments for this population is needed as is the use of batteries offering greater specificity and sensitivity for the detection of cognitive impairment
\end{abstract}

Key words: Parkinson's disease, cognition, deep brain stimulation.

\section{INTRUMENTOS DE AVALIAÇÃO COGNITIVA EM INDIVÍDUOS COM DOENÇA DE PARKINSON SUBMETIDOS À ESTIMULAÇÃo CEREBRAL PROFUNDA}

RESUMO. A Estimulação Cerebral Profunda (ECP) tem sido uma técnica cirúrgica bastante utilizada devido à redução significativa dos sintomas motores. Objetivos: Verificar, a partir das publicações, quais os instrumentos mais utilizados para avaliação cognitiva em pacientes com DP submetidos à ECP. Métodos: Foi realizado uma revisão sistemática nas bases de dados PubMed, Medline, EBECS, Scielo e LILACS utilizando os descritores "Deep Brain Stimulation", "Verbal Fluency", "Parkinson Disease", "Executive Function", "Cognition" e "Cognitive Assessment" de forma combinada. Resultados: 0 teste de Fluência Verbal o instrumento mais utilizado para esta investigação nos estudos encontrados, seguido pelo Teste de Nomeação de Boston. Foram também encontradas referências aos testes Teste de Stroop, Teste das Trilhas, Teste de Aprendizado Auditivo Verbal de Rey. Conclusões: A validação de instrumentos para esta população se faz necessária bem como a utilização de baterias com mais especificidade e sensibilidade para detecção das alterações cognitivas nesta população. Palavras-chave: doença de Parkinson, cognição, estimulação cerebral profunda.

\section{INTRODUCTION}

Tremor, bradykinesia and rigidity are the 1 main sources of discomfort reported by Parkinson's disease patients. In addition to the motor symptoms that affect activities of daily living (ADL) and the quality of communications and eating, PD has other symptoms. Cognitive changes occur, in most cases, in the more advanced stages of the disease, preceded by psychiatric signs, such as hallucinations and psychosis. ${ }^{1}$ Other symptoms such as depression, may be present from the early stages of PD. ${ }^{2}$

Many treatment options have been developed since the discovery of this disease, such as new medications, technology and surgical techniques, as well as rehabilitation. However, drugs do not mitigate or delay disease

\footnotetext{
'Mestranda em Medicina, Ciências Médicas, Universidade Federal do Rio Grande do Sul, Porto Alegre RS, Brazil (UFRGS). Fonoaudióloga Clínica. ²Doutora em Ciências da Criança e do Adolescente, UFRGS. Professora Adjunto da UFRGS, Departamento de Psicologia do Desenvolvimento e da Personalidade. ${ }^{3}$ Mestre em Medicina e Ciências da Saúde, Pontifícia Universidade Católica do Rio Grande do Sul, Porto Alegre RS. Brazil (PUCRS). Neuropsicóloga do Laboratório de Estudos Cognitivos, MemoLab (Hospital Moinhos de Vento). ${ }^{4}$ Doutor em Clinical Neuroscience (University of Birmingham). Professor Adjunto de Neurologia da Universidade Federal de Ciências da Saúde de Porto Alegre (UFCSPA) e do Programa de Pós Graduação em Medicina, Ciências Médicas, UFRGS. ${ }^{5}$ Doutora em Educação, UFRGS. Professora Adjunto do Curso de Fonoaudiologia da UFRGS, Departamento de Cirurgia e Ortopedia.
}

Aline Juliane Romann. Rua Dr. Otávio Santos, 571 / 907 - 91210-001 Porto Alegre RS - Brazil. E-mail: a.romann@hotmail.com

Disclosure: The authors report no conflicts of interest. Received December 27, 2011. Accepted in final form February 27, 2012. 
symptoms, and a cure for PD remains an elusive challenge among researchers.

Deep Brain Stimulation (DBS) is a stereotactic technique in which two leads fitted with four electrodes are implanted in the region of the basal ganglia. The treatment is indicated for patients with PD undergoing treatment with drugs and who present with further complications, such as dyskinesia, motor fluctuations and refractory tremor. ${ }^{3}$ The motor gains acquired as a result of the neuronal inhibition provided by the neurostimulator are significant. ${ }^{4}$ However, DBS may have a negative impact on both communication skills $s^{5}$ and cognitive symptoms. ${ }^{6,7}$

In 2007, the Movement Disorder Society (MDS) proposed criteria and instruments for diagnosing and classifying dementia in Parkinson Disease patients (PDD). As the screening tool for diagnosing PD-D, the MSD proposed the Mini Mental State Examination (MMSE); the Months Reversed, Lexical Fluency (LV) and Clock Drawing (CD) tests. To provide a more detailed series of assessments allowing characterization of the components of PD-D, the MSD recommended the following tests: the Mattis Dementia Rating Scale (MDRS), Digit Span (DS), Spatial Span from the CANTAB, Digit Ordering (DO), Similarities of the WAIS-R, Wisconsin Card Sorting Test (WCST), Verbal Fluency (VF), Trail Making Test (TMT), Stroop Test (ST), Odd Man Out Test (OMO), Prehension Behavior (PB), Apathy Scale (AS), the Neuropsychiatric Inventory (NPI), Montgomery and Asberg Depression Rating Scale (MADRS), Hamilton Depression Rating Scale (HDRS), Beck Depression Inventory (BDI), Geriatric Depression Scale (GDS), Parkinson Psychosis Questionnaire (PPQ), Rey Auditory Verbal Learning Test (RAVL), Free and Cued Recall Test (FC), Boston Naming test (BNT), Benton Line Orientation Test (BLO) and Benton Face Recognition Test (BFO) or the Fragmented Letters of the VOSP. ${ }^{8}$

The American Academy of Neurology (AAN) listed instruments for the cognitive and neuropsychiatric examination of individuals with PD. To investigate psychiatric symptoms, the AAN suggested the use of the BDI, the HDRS, the Hamilton Anxiety Rating Scale (HARS), the Brief Psychiatric Rating Scale (BPRS), the Schedule for the Assessment of Positive Symptoms (SAPS), the AS and NPI; whereas for cognitive investigations, the AAN suggested the Cambridge Cognitive Examination (CAMCog), the Alzheimer's Disease Assessment Scalecognitive (ADAS COG), the Addenbrooke's Cognitive Examination - Revised (ACE-R), the Clinician Global Impression of Change (CGIC), the Montreal Cognitive Assessment (MoCA), the MDRS, the Parkinson Neuro- psychometric Dementia Assessment (PANDA), the Parkinson's Disease-Cognitive Rating Scale (PD-CRS), the Scales for Outcomes of Parkinson's Disease - Cognition (SCOPA-COG), the Short Portable Mental Status Questionnaire (SPMSQ) and the MMSE. ${ }^{9}$ However, patients that undergo DBS implantation can have a wide variety of cognitive symptoms, and the best instruments for evaluation are not well established.

This study identified which instruments are used for the cognitive evaluation of patients with PD undergoing DBS.

\section{METHODS}

A systematic review of the literature was conducted including all publications available in PUBMED, MEDLINE, LILACS, EBECS and SCIELO. In order to conduct a broad-based literature review, the search included studies published since 1997, representing the date of the first publication evaluating cognitive aspects of patients with PD in the databases reviewed. The search was conducted using the following key words: "Parkinson disease" and "deep brain stimulation" combined with "verbal fluency", "cognition", "executive function" or "cognitive assessment".

The studies, reviewed independently by three examiners, were selected according to the following inclusion criteria:

- Published between 1997 and 2011;

- Original studies involving human beings;

- Studies whose objective was the cognitive assessment of patients with PD that received unilateral or bilateral DBS;

- At least one instrument of cognitive assessment;

- Positive or negative cognitive results.

Studies not meeting these criteria were excluded. To ensure that all examiners had the same criteria to evaluate abstracts, a data collection form (Appendix A) with the criteria described above was devised and filled out for each study. Each assessor assigned a grade from 0 to 10 to each study. Studies graded below 8 were excluded from this review.

\section{RESULTS}

A total of 523 studies were found in the databases used of which 473 were excluded: 258 because they were the same study indexed in different databases, and 215 due to other exclusion criteria. Fifty studies were included in this review, $, 7,10-58$ and 90 instruments were found: 71 tests and 19 scales. Given the large number of instruments, only those used in more than 10 of the studies included in this review are described below. All inven- 
tories and scales found are listed in Tables 1 and 2. To facilitate comprehension, and because the same instrument might evaluate more than one cognitive aspect, instruments were classified according to the predominant cognitive function assessed: attention, perception, memory, language, dexterity, executive functions, cognitive screening tests, intelligence, and laterality in handedness. Similarly, scales were classified according to whether they investigated depression, anxiety, mood, apathy, psychiatric disorders and quality of life. This classification was based on the suggestions proposed by Lezak (2004). ${ }^{59}$

\section{Cognitive assessment tests of PD patients undergoing DBS}

Attention tests - The instrument most often used for attention was the Stroop Test (ST), found in 21 studies. This test, developed by John Ridley Stroop in 1935, is aimed at evaluating selective attention, inhibitory capacity and concentration. This test has some variations, but the full format has the following stages. Scores may be defined according to test performance time, number of errors or both, or according to the number of items read or named within a given timeframe. ${ }^{59}$

The ST was standardized by Tosi $(2004)^{59}$ for use in Brazilian populations, and was tested for Brazilian students aged 12 to 14 years to obtain normative data for this population. ${ }^{61}$ However, this test has not been standardized for adult and elderly Brazilians, nor validated for individuals with PD.

Cognitive aspects, such as visual attention, processing speed, flexibility and planning, have been evaluated in 20 studies using the Trail Making Test (TMT), which originated from the Army Individual Test Battery (1944) and has two parts, A and B. The score is defined according to time taken, i.e. the test should be completed as fast as possible. ${ }^{59}$

The TMT was used for a Brazilian population by Hamdan and Hamdan (2009), ${ }^{62}$ who found that age and schooling affected individual scores, and that there was a significant increase in the time required to complete the TMT tasks according to the individual's age. Also, mean time taken decreases with greater schooling.

Memory test - The Digit Span (DS) test, part of the Wechsler Adult Intelligence Scale (WAIS), was used individually in 11 studies, and together with the WAIS in 7 studies. Scores are defined by the number of correct answers. Adults without deficits are expected to repeat at least 5 numbers in direct order and at least 3 in inverse order. Age tends to affect performance only for individuals $>65$ years old, for whom the normal score is 5 right answers. ${ }^{59}$
The DS test alone has not been standardized for Brazilian populations or individuals with PD. However, together with the WAIS, it was standardized for a Brazilian population by Nascimento et al. (1998) ${ }^{63}$ and validated for a population with PD by Randolph et al. (1993). ${ }^{64}$

A test used in 14 studies to evaluate immediate, short- and long-term memory was the Rey's Auditory Verbal Learning Test (RAVLT), developed by Rey in 1964. This test has several variations, but the one most often used consists of three parts. The RAVLT learning score is the sum of words remembered, with the maximum score again 15 , and the closer the result to this number, the better the performance. ${ }^{59}$

In Brazil, Malloy-Diniz et al. (2007) ${ }^{65}$ developed a version of RAVLT with nouns frequently used in Portuguese, and applied it to groups of elderly individuals aged 60 to 89 years. The authors found that the Brazilian adaptation of the RAVLT was appropriate and evaluated the memory of Brazilian individuals of the same age and schooling. In 2009, Teruyaet al. ${ }^{66}$ conducted a pilot study to evaluate the performance of normal Brazilian adults using the RAVLT. The group found that overall test performance decreased as age increased, and that schooling was positively associated with scores. In 2010, Fichmanet al ${ }^{67}$ published a study to validate the RAVLT. The authors found a strong association between episodic memory and sociodemographic variables. This finding is relevant in a country like Brazil, where educational levels vary substantially. However, further studies should be conducted to test the effect of age and schooling on RAVLT performance.

Language tests - The Verbal Fluency test, used in 37 studies, was the most frequent test employed to evaluate executive functions, language and semantic memory. The phonological VF (FAS) prompts the respondent to name words starting with the letters F, A and S, excluding proper names, numbers, the same word with different suffixes, or different conjugations of the same verb. A time of 1 minute is assigned for each letter. ${ }^{59}$ The test was normalized by Tombaugh et al. $(1998)^{68}$ but no studies have been found on FAS validation for populations with PD.

The VF test has a variation, a semantic restriction, in which the individual has 1 minute to produce words limited to one semantic class (animals, fruit, foods, etc.). This instrument variation evaluates the capacity to search and retrieve data stored in long-term memory within a certain category and to demonstrate the capacities of organization, self-regulation and operational memory. This variation was validated for the Brazilian population by Brucki et. al (1997;2004). ${ }^{69,70}$ 
Table 1. Tests and Cognitive Screening Batteries used in the studies, classified according to the predominant cognitive function tested.

\begin{tabular}{|c|c|c|}
\hline $\begin{array}{l}\text { Cognitive } \\
\text { function }\end{array}$ & Tests & $\begin{array}{l}\text { Number } \\
\text { of studies }\end{array}$ \\
\hline \multirow[t]{12}{*}{ Attention } & Stroop Test & 21 \\
\hline & Trail Making Test & 20 \\
\hline & Corsi's Block Tapping Test & 8 \\
\hline & Go-No-Go Task & 3 \\
\hline & Symbol Digital Modalities Test & 1 \\
\hline & N-Back Task & 1 \\
\hline & Oral Trail Making Test & 1 \\
\hline & Spinler Matrices Test & 1 \\
\hline & Color Word Interference Test (D-KEFS) & 1 \\
\hline & Visual Reaction Time (Vrt) & 1 \\
\hline & $\begin{array}{l}\text { Money's Standardised Road Map Test for } \\
\text { Direction Sense (Mrmt) }\end{array}$ & 1 \\
\hline & Test For Attentional Performance (Tap) & 1 \\
\hline \multirow{2}{*}{$\begin{array}{l}\text { Visual } \\
\text { Perception }\end{array}$} & Hooper Visual Organizational Test & 2 \\
\hline & $\begin{array}{l}\text { The Visual Object and Space Perception } \\
\text { Battery (Vosp) }\end{array}$ & 1 \\
\hline \multirow[t]{22}{*}{ Memory } & Rey's Auditory Verbal Learning Test & 14 \\
\hline & Digit Span & 11 \\
\hline & Wechsler Memory Scale & 6 \\
\hline & Paired Associate Learning & 4 \\
\hline & Benton Visual Retention Test & 4 \\
\hline & Grober And Buschke Verbal Learning Test & 3 \\
\hline & Benton Line Orientation Test & 3 \\
\hline & Random Number Generation Task (Rngt) & 2 \\
\hline & California Verbal Learning Test & 2 \\
\hline & Hopkins Verbal Learning Test & 2 \\
\hline & Logical Memory Task & 2 \\
\hline & Rey Osterrieth Complex Figure Test & 2 \\
\hline & Brief Visuospatial Memory Test & 1 \\
\hline & Visual Conditional Learning Test & 1 \\
\hline & Benton Judgment Of Line Orientation Test & 1 \\
\hline & Rey Figure/Taylor Figure & 1 \\
\hline & Memory Assessment Clinics Rating (Mac) & 1 \\
\hline & Rivermead Behavioural Memory Test & 1 \\
\hline & Rey-Kim Memory Battery & 1 \\
\hline & Brief Visual Memory Test & 1 \\
\hline & Conditional Associative Learning Test (CALT) & 1 \\
\hline & Externally Ordered Working Memory Test & 1 \\
\hline
\end{tabular}

Table 1. Continuation.

\begin{tabular}{|c|c|c|}
\hline $\begin{array}{l}\text { Cognitive } \\
\text { function }\end{array}$ & Tests & $\begin{array}{l}\text { Number } \\
\text { of studies }\end{array}$ \\
\hline \multirow[t]{10}{*}{ Language } & Verbal Fluency & 37 \\
\hline & Boston Naming Test & 12 \\
\hline & Controlled Oral Word Association Test & 6 \\
\hline & Bi-Syllabic words Repetition Test & 6 \\
\hline & Boston Diagnostic Aphasia Examination & 1 \\
\hline & Regensburg Word Fluency Test (RWT) & 1 \\
\hline & $\begin{array}{l}\text { Syntactic Comprehension Test and } \\
\text { Morphological Test }\end{array}$ & 1 \\
\hline & Agnosia Screening Task of Schnider & 1 \\
\hline & ABBA & 1 \\
\hline & North American Adult Reading Test & 1 \\
\hline \multirow[t]{3}{*}{ Construct } & Clock Drawing & 1 \\
\hline & Grooved Pegboard Test & 1 \\
\hline & Purdue Pegboard Test & 1 \\
\hline \multirow{12}{*}{$\begin{array}{l}\text { Executive } \\
\text { functions }\end{array}$} & Wisconsin Card Sorting Test & 17 \\
\hline & Raven's Progressive Matrices & 10 \\
\hline & Modified Wisconsin Card Sorting Test & 4 \\
\hline & Frontal Assessment Battery & 3 \\
\hline & Tower of London & 2 \\
\hline & $\begin{array}{l}\text { Dex Questionnaire of the Behavioural } \\
\text { Assessment of the Dysexecutive Syndrome }\end{array}$ & 1 \\
\hline & Paced Auditory Serial Addition Task & 1 \\
\hline & Paced Visual Serial Addition Test & 1 \\
\hline & Frontal systems behavior scale & 1 \\
\hline & Odd Man Out Test & 1 \\
\hline & $\begin{array}{l}\text { Vocabulary and Reasoning of The } \\
\text { "Leistungsprufsystem" (LPS) }\end{array}$ & 1 \\
\hline & Homophone Meaning Generation Test & 1 \\
\hline \multirow{6}{*}{$\begin{array}{l}\text { Cognitive } \\
\text { Screening } \\
\text { Batteries }\end{array}$} & Mini Mental State Examination & 18 \\
\hline & Mattis Dementia Rating Scale & 15 \\
\hline & Dementia Rating Scale & 7 \\
\hline & Dutch Adult Reading Test & 1 \\
\hline & National Adult Reading Test & 1 \\
\hline & Cerad Neuropsychological Battery & 1 \\
\hline \multirow[t]{3}{*}{ Intelligence } & Wechsler Adult Intelligence Scale & 7 \\
\hline & Groningen Intelligence Test & 1 \\
\hline & Verbal Intelligence Quotient & 1 \\
\hline $\begin{array}{l}\text { Laterality of } \\
\text { Handedness }\end{array}$ & Edinburgh Handedness Inventory & 1 \\
\hline
\end{tabular}


Table 2. Scales used in the studies

\begin{tabular}{lll}
\hline & Scales & Number of studies \\
\hline Depression & Beck Depression Inventory & 20 \\
\cline { 2 - 3 } & Montgomery-Asberg Depression Rating Scale & 6 \\
\cline { 2 - 3 } & Hamilton Depression Rating Scale & 2 \\
\cline { 2 - 3 } & Geriatric Depression Scale & 1 \\
\cline { 2 - 3 } & Hospital Anxiety And Depression Scale & 1 \\
\cline { 2 - 3 } & Brief Symptom Inventory & 4 \\
\hline Anxiety & State-Trait Anxiety Inventory & 1 \\
\cline { 2 - 3 } & Beck Anxiety Inventory & 1 \\
\cline { 2 - 3 } & Hamilton Anxiety Rating Scales & 1 \\
\cline { 2 - 3 } & Snaith-Hamilton pleasure Scale & 1 \\
\cline { 2 - 3 } & Maudsley Obsessional Compulsive Inventory & 1 \\
\hline Mood & Visual Analogue Mood Scale & 1 \\
\cline { 2 - 3 } & Positive And Negative Affect Scale & 1 \\
\cline { 2 - 3 } & Profile Of Mood States & 1 \\
\hline Apathy & Apathy Scale & 1 \\
\cline { 2 - 3 } & Apathy Evaluation Scale & 1 \\
\hline Psychiatric & Neuropsychiatric Inventory & 1 \\
\cline { 2 - 3 } & Bech-Rafaelsen Mania Scale & 1 \\
\hline & Parkinson's Disease Questionnaire (PDQ-39) & 1 \\
\hline
\end{tabular}

The Boston Naming Test (BNT) was used in 12 studies to evaluate language skills and semantic memory by naming figures. Developed by Kaplan, Goodglass and Weintraub in 1978, it consists of the presentation of 60 items drawn in black and white, graded according to difficulty parameters, which the individual has to name spontaneously in 20 seconds. This test was validated for a Brazilian population by Miotto et al. (2010). ${ }^{71}$ In this adapted version, the authors replaced 20 figures to take into consideration cultural familiarity, frequency, ambiguity and similarity with the original figure. The authors found that the adapted version was less dependent on schooling and age than the original version, and may thus be more appropriate for clinical applications. However, the test has not been standardized for populations with $\mathrm{PD}$.

Executive function tests - The objective of the Wisconsin Card Sorting Test (WCST) is to evaluate components of the executive functions of categorizing, conceptualizing, planning, learning, perseveration of rules and successful strategies, and cognitive flexibility. This test was used in 17 studies to evaluate the main cognitive impairments in PD. The WCST has been adapted and standardized for use in Brazil and for restricted use of psychologists. ${ }^{72}$
Raven's Progressive Matrices (RPM) consists of a set of nonverbal tests of problem resolution involving the use of reasoning and efficacious strategies, discovery of rules and applications of mental operations. This test, used in 10 studies, has three versions: the Standard Progressive Matrices (SPM), for use with individuals of all levels of intellectual development; the Colored Progressive Matrices (CPM), for young children, elderly individuals and people with mental deficiencies; the Advanced Progressive Matrices (APM), developed for people with above average intellectual capacity, and usually indicated for university students. ${ }^{59}$ In Brazil, RPM has been validated only for children by Pasquali et al. (2002), ${ }^{73}$ who defined normative data for a population of children in the city of Porto Alegre. However, it has not yet been validated for Brazilian adults, elderly adults, or individuals with PD.

Cognitive screening tests - The most frequently used cognitive screening battery was the Mini Mental State Examination (MMSE), applied in 18 studies. The MMSE tests the integrity of mental functions in a rapid and simple way. It evaluates the following functions: orientation to time and place, memory, attention, calculus, language and construct ability. Scores are defined according to points, which range from 0 to 30 . The vari- 
ables that affect total MMSE score have been intensively discussed among researchers. Studies suggest that age and schooling of the Brazilian population have a strong influence on performance on the tasks in the MMSE. This discussion led to the validation of the $\mathrm{MMSE}^{74,75}$ scale for the Brazilian population and the definition of new scores according to age and schooling. At the same time, a recent study ${ }^{76}$ evaluated the impact of education on the MMSE subscales and items. Results revealed that schooling has no effect on naming tasks, three-stage commands, memory recall or delayed memory. Memory is a key factor in diagnosing dementia; therefore, these items may be included in the evaluation irrespective of level of education.

The Mattis dementia rating scale (MDRS), a cognitive screening battery that also evaluates general cognitive status, was used in 15 studies. This scale consists of 36 individual tasks divided into 5 subscales: attention (8 items, 37 points); initiation and perseveration (11 items, 37 points), construct (6 items, 6 points), conceptualization (6 items, 39 points) and memory (5 items, 25 points), giving a total score of 144 points. The cut-off score for absence of dementia in the Brazilian population is 122 points; scores below this level indicate a demential process.

In 2003, Porto et al. ${ }^{77}$ developed a Portuguese version of the MDRS and applied it to a group of individuals with Alzheimer's disease (AD), comparing them with a group of healthy elderly individuals. The authors concluded that the MDRS had good diagnostic accuracy to discriminate between patients with mild $\mathrm{AD}$ and control individuals. In the study population, the effects of schooling were more marked than those of age. This result was confirmed by Foss et al. (2005), ${ }^{78}$ who investigated the influence of low schooling and illiteracy on the evaluation of dementia by applying the MDRS. They found that schooling affects performance and concluded that illiteracy is a factor determining lower MDRS scores, which may generate diagnostic errors.

Scales for evaluating depression symptoms - The Beck Depression Inventory (BDI), in the form of a self-administered questionnaire, was used in 20 studies to evaluate the intensity of depression. This instrument has 21 items for symptoms and attitudes, describing behavioral, affective, cognitive and somatic signs of depression. Each item has four response alternatives in the form of statements, organized according to severity with scores that range from 0 to 3 . The overall evaluation of depression is defined according to the sum of the numbers that correspond to the answers. According to the inventory, a sum of 0 to 9 is within the limits of nor- mality, a result from 10 to 15 suggests mild depression; from 16 to 23 , moderate depression, and 24 or more, severe depression.

The BDI was validated for the Brazilian population by Gorenstein and Andrade ${ }^{79}$ in 1986. The Hamilton Depression Rating Scale and the State-Trait Anxiety Inventory were used for comparisons: the BDI was more efficacious, and its reliability ranged from moderate to good.

Of the 89 instruments used, 20 have been tested for the Brazilian population ${ }^{60,62,63,65,67,69-72,74-77,79-83,86,88,92-94}$ and 12 have been standardized for populations with PD. ${ }^{64,84,85,87,89-91,95}$ The instruments tested for the Brazilian population and for individuals with PD are listed in Table 3.

\section{DISCUSSION}

The purpose of the studies included in this systematic review was to evaluate the cognition of patients with PD that underwent DBS and to investigate the impact of the neurostimulator on cognitive performance. The results showed the diversity of instruments used. There is no consensus on the use of a single test or scale, or on the cognitive functions to be evaluated.

The application of only one test is insufficient to evaluate cognition, and a group of instruments is usually applied to obtain more reliable data, given the lack of standardized instruments for PD patient groups and disagreement concerning the predominant cognitive functions in decline. According to instrument classifications, the functions most frequently evaluated were language (74.5\%), memory (72.2\%), attention (66.7\%) and executive functions (47.7\%). These functions may be impaired because of the disease, but studies in the literature draw attention to the decline of executive skills, which may be present in the initial stages of the disease. ${ }^{96}$ However, as demonstrated above, the use of tests for the evaluation of this function was less frequent.

Of the instruments recommended by the AAN and MDS for cognitive screening, the most frequently used were the MMSE and the MDRS. The MMSE is one of the most frequently used cognitive screening instruments for investigating cognitive decline in the elderly. However, because of the cognitive impairments in PD, studies have shown this not to be the best cognitive screening instrument for this population. Hoops et al. $(2009)^{84}$ evaluated the discriminating validity of the MoCA and the MMSE for detecting mild cognitive impairment (MCI) and dementia in PD. They found that the MoCA had appropriate psychometric properties as a screening instrument for detecting $\mathrm{MCI}$ and dementia 
Table 3. Instruments tested for the Brazilian population and for populations with PD.

\begin{tabular}{|c|c|c|}
\hline Test/Scale & $\begin{array}{l}\text { Instrument tested for } \\
\text { Brazilian population }\end{array}$ & $\begin{array}{c}\text { Instrument tested for } \\
\text { population with PD }\end{array}$ \\
\hline Stroop Test ${ }^{3}$ & $\checkmark$ & $\mathrm{x}$ \\
\hline Trail Making Test ${ }^{64}$ & $\checkmark$ & $\mathrm{x}$ \\
\hline Rey's Auditory Verbal Learning Test'67,69 & $\checkmark$ & $\mathrm{x}$ \\
\hline Rivermead Behavioural Memory Test ${ }^{82}$ & $\checkmark$ & $\mathrm{x}$ \\
\hline Verbal Fluency ${ }^{71,72}$ & $\checkmark$ & $x$ \\
\hline Boston Naming Test ${ }^{73}$ & $\checkmark$ & $\mathrm{x}$ \\
\hline Boston Diagnostic Aphasia Examination ${ }^{83}$ & $\checkmark$ & $x$ \\
\hline Dex Questionnaire of the Behavioural Assessment of the Dysexecutive Syndrome ${ }^{82}$ & $\checkmark$ & $\mathrm{x}$ \\
\hline Wisconsin Card Sorting Test ${ }^{72}$ & $\checkmark$ & $x$ \\
\hline Frontal Assessment Battery ${ }^{83}$ & $\checkmark$ & $x$ \\
\hline Mini Mental State Examination $74-76,84$ & $\checkmark$ & $\checkmark$ \\
\hline Mattis Dementia Rating Scale 77,85 & $\checkmark$ & $\checkmark$ \\
\hline Dementia Rating Scale ${ }^{86,87}$ & $\checkmark$ & $\checkmark$ \\
\hline Wechsler Adult Intelligence Scale ${ }^{63,64}$ & $\checkmark$ & $\checkmark$ \\
\hline Edinburgh Handedness Inventory ${ }^{88}$ & $\checkmark$ & $\mathrm{x}$ \\
\hline Beck Depression Inventory ${ }^{79,89}$ & $\checkmark$ & $\checkmark$ \\
\hline Montgomery-Asberg Depression Rating Scale ${ }^{90}$ & $\mathrm{x}$ & $\checkmark$ \\
\hline Hamilton Depression Rating Scale ${ }^{90}$ & $x$ & $\checkmark$ \\
\hline State-Trait Anxiety Inventory ${ }^{79}$ & $\checkmark$ & $x$ \\
\hline Hamilton Anxiety Rating Scales ${ }^{91}$ & $x$ & $\checkmark$ \\
\hline Hospital Anxiety And Depression Scale ${ }^{92}$ & $\checkmark$ & $\checkmark$ \\
\hline Beck Anxiety Inventory ${ }^{91}$ & $x$ & $\checkmark$ \\
\hline Bech-Rafaelsen Mania Rating Scale ${ }^{93}$ & $\checkmark$ & $x$ \\
\hline Parkinson's Disease Questionnaire (PDQ-39) & $\checkmark$ & $\checkmark$ \\
\hline
\end{tabular}

in $\mathrm{PD}$, and that it is therefore more sensitive than the MMSE in this population. Along the same lines, HannaPladdy et al. (2010) ${ }^{97}$ conducted a comparative study of the MoCA, the MMSE and the NeuroTrax battery. Results suggested that the MoCA was the most sensitive for investigating MCI in PD.

The MDRS also has good diagnostic accuracy to investigate cognitive functioning of individuals with PD. It was validated as a screening instrument for cognitive dysfunction in this population by Brown et al. (1999), ${ }^{87}$ and proved more sensitive to variations in thelevel of cognitiveimpairment than the MMSE. Llebaria etal.(2008) ${ }^{85}$ conducted a study to validate the MDRS for dementia screening in PD. Their results revealed that the MDRS has an excellent discriminating ability for diagnosing dementia in $\mathrm{PD}$, and provides objective measurements.

Of the instruments proposed by the MDS for the classification of PD-D, the most often used were the DS,
WCST, VF, TMT, ST, BNT, RAVLT and BDI. The recommendations made by the MDS are more extensive, including several cognitive domains for which PD patients may show decline. Since the implementation of DBS is contraindicated for PD-D, the use of various instruments to assess preoperative cognitive function is necessary for optimal indication of the procedure.

Of the main scales used to evaluate depression, mood and anxiety among individuals with PD, the BDI and the MDRS were previously evaluated to check their accuracy and correlation with clinical diagnoses by Silberman et al. (2006). ${ }^{98}$ The authors found positive results and suggested the use of a cut-off point of 10 for the MDRS and 18 for the BDI to help clinicians detect depression in mild and moderate PD. The use of these scales to investigate depressive symptoms was also recommended by Schrag et al. (2007), ${ }^{99}$ who also suggested that the BDI could be used to monitor depressive symptoms in rela- 
tion to clinical or surgical treatment of PD. However, the clinical aspects of depression were not evaluated, and depression was only monitored using the BDI.

This review showed that there is no consensus on the instruments used in the evaluations of individuals with PD that underwent DBS. The AAN has recommended some instruments suitable for evaluating cognitive decline in populations with PD, but they have not been used frequently. Moreover, instruments applied should be standardized for use with this population.
The analysis of cognitive functions revealed that evaluations in this population with PD focused largely on language and memory. Studies in the literature showed that PD leads to a decline predominantly in executive functions, indicating that individuals undergoing DBS may suffer different impacts and that it is necessary to use instruments to assess both cognitive functions in order to obtain more reliable results.

Study conducted under the Post-Graduate Psychology Program - Specialization in Speech Therapy with focus on Aging (UFRGS).

\section{REFERENCES}

1. Levy G, Tang MX, Cote LJ, et al. Motor impairment in PD: relationship to incident dementia and age. Neurology 2000;55:539-544.

2. Schuurmann AG, Akker M, Ensinck KTJL, et al. Increased risk of Parkinson's disease after depression. A retrospective cohort study. Neurology 2002;58:1501-1504.

3. Perriol MP, Krystkowiak P, Defebvre L, Blond S, Destée A, Dujardin K. Stimulation of the subthalamic nucleus in Parkinson's disease: Cognitive and affective changes are not linked to the motor outcome. Parkinsonism Relat Disord 2006;12:205-210.

4. Weaver FM, Follett K, Stern M, et. al. Bilateral deep brain stimulation vs best medical therapy for patients with advanced parkinson disease a randomized controlled trial. JAMA 2009;301:63-73.

5. Törnqvist AL, Schalén L, Rehncrona S. Effects of different electrical parameter settings on the intelligibility of speech in patients with Parkinson's disease treated with subthalamic deep brain stimulation. Mov Disord 2005;20:416-423.

6. Contarino MF, Daniele A, Sibilia AH, et al. Cognitive outcome 5 years after bilateral chronic stimulation of subthalamic nucleus in patients with Parkinson's disease. J Neurol Neurosurg Psychiatry 2007;78:248-252.

7. Wojtecki L, Timmermann L, Jörgens S, et al. Frequency-dependent reciprocal modulation of verbal fluency and motor functions in subthalamic deep brain stimulation. Arch Neurol 2006;63:1273-1276.

8. Dubois B, Burn D, Goetz C, et al. Diagnostic procedures for Parkinson's disease dementia: recommendations from the Movement Disorder Society Task Force. Mov Disord 2007;22:2314-2324.

9. Miyasaki JM, Shannon K, Voon V, et al. Practice parameter: evaluation and treatment of depression, psychosis and dementia in Parkinson disease (an evidence-based review). Neurology 2006;66:996-1002.

10. Vingerhoets G, Van Der Linden C, et al. Cognitive outcome after unilateral pallidal stimulation in Parkinson's disease. J Neurol Neurosurg Psychiatry 1999;66:297-304.

11. Ardouin C, Pillon B, Peiffer E, et al. Bilateral subthalamic or pallidal stimulation for Parkinson's disease affects neither memory nor executive functions:a consecutive series of 62 patients. Ann Neurol 1999;46: 217-223.

12. Alegret $M$, Junqué $C$, Valldeoriola $F$, et al. Effects of bilateral subthalamic stimulation on cognitive function in Parkinson disease. Arch Neurol 2001;58:1223-1227.

13. Perozzo P, Rizzone M, Bergamasco B, et al. Deep brain stimulation of the subthalamic nucleus in Parkinson's disease: comparison of pre- and postoperative neuropsychological evaluation. J NeurolSci 2001;192: 9-15.

14. Funkiewiez A, Ardouin C, Caputo E, et al. Long term effects of bilateral subthalamic nucleus stimulation on cognitive function, mood, and behaviour in Parkinson's disease. J Neurol Neurosurg Psychiatry 2004;75:834-839

15. Loher TJ, Gutbrod K, Fravi NL, et al. Thalamic stimulation for tremor. Subtle changes in episodic memory are related to stimulation per se and not to a microthalamotomy effect. J Neurol 2003;250:707-713

16. Moretti R, Torre P, Antonello RM, et al. Neuropsychological changes after subthalamic nucleus stimulation:a 12 month follow-up in nine patients with Parkinson's disease. Parkinsonism Relat Disord 2003;10: 73-79.
17. Fasano A, Romito LM, Daniele A, et al. Motor and cognitive outcome in patients with Parkinson's disease 8 years after subthalamic implants. Brain 2010;133:2664-2676.

18. Bickel S, Alvarez L, Macias R, et al. Cognitive and neuropsychiatric effects of subthalamotomy for Parkinson's disease. Parkinsonism Relat Disord 2010;16:535-539.

19. Castelli L, Rizzi L, Zibetti M, Angrisano S, Lanotte M, Lopiano L. Neuropsychological changes 1-year after subthalamic DBS in PD patients: a prospective controlled study. Parkinsonism Relat Disord 2010;16: 115-118.

20. York MK, Wilde EA, Simpson R, Jankovic J. Relationship between neuropsychological outcome and DBS surgical trajectory and electrode location. J Neurol Sci 2009;287:159-171.

21. Zangaglia R, Pacchetti C, Pasotti C, et al. Deep brain stimulation and cognitive functions in Parkinson's disease:A three-year controlled study. Mov Disord 2009;24:1621-1628.

22. Zahodne LB, Okun MS, Foote KD, et al. Greater improvement in quality of life following unilateral deep brain stimulation surgery in the globuspallidus as compared to the subthalamic nucleus. J Neurol 2009;256:1321-1329.

23. Okun MS, Fernandez HH, Wu SS, et al. Cognition and mood in Parkinson's disease in subthalamic nucleus versus globuspallidusinterna deep brain stimulation:the COMPARE trial. Ann Neurol 2009;65:586-595.

24. Zahodne LB, Okun MS, Foote KD, et al. Cognitive declines one year after unilateral deep brain stimulation surgery in Parkinson's disease: a controlled study using reliable change. Clin Neuropsychol 2009;23: 385-405.

25. Castner JE, Copland DA, Silburn PA, Coyne TJ, Sinclair F, Chenery HJ. Subthalamic stimulation affects homophone meaning generation in Parkinson's disease. J Int Neuropsychol Soc 2008;14:890-894.

26. Heo JH, Lee KM, Paek SH, Kim MJ, Lee JY, Kim JY.The effects of bilateral subthalamic nucleus deep brain stimulation (STN DBS) on cognition in Parkinson disease. J Neurol Sci 2008;273:19-24.

27. Higginson Cl, Wheelock VL, Levine D, King DS, Pappas CT, Sigvardt KA. The clinical significance of neuropsychological changes following bilateral subthalamic nucleus deep brain stimulation for Parkinson's disease. J Clin Exp Neuropsychol 2009;31:65-72.

28. Witt K, Daniels C, Reiff J, et al. Neuropsychological and psychiatric changes after deep brain stimulation for Parkinson's disease: a randomised, multicentre study. Lancet Neurol 2008;7:605-614.

29. York MK, Dulay M, Macias A, et al. Cognitive declines following bilateral subthalamic nucleus deep brain stimulation for the treatment of Parkinson's disease. J Neurol Neurosurg Psychiatry 2008;79:789-795.

30. Castelli L, Lanotte M, Zibetti M, et al. Apathy and verbal fluency in STN-stimulated PD patients.An observational follow-up study. J Neurol 2007;254:1238-1243.

31. Cilia R, Siri C, Marotta G, et al. Brain networks underlining verbal fluency decline during STN-DBS in Parkinson's disease:an ECD-SPECT study. Parkinsonism Relat Disord 2007;13:290-294.

32. Rothlind JC, Cockshott RW, Starr PA, Marks WJ Jr. Neuropsychological performance following staged bilateral pallidal or subthalamic nucleus deep brain stimulation for Parkinson's disease. J Int Neuropsychol Soc 2007;13:68-79. 
33. De Gaspari D, Siri C, Di Gioia M, Antonini A, Isella V, Pizzolato A et al. Clinical correlates and cognitive underpinnings of verbal fluency impairment after chronic subthalamic stimulation in Parkinson's disease. Parkinsonism Relat Disord 2006;12:289-295.

34. Erola T, Heikkinen ER, Haapaniemi T, Tuominen J, Juolasmaa A, Myllylä W. Efficacy of bilateral subthalamic nucleus (STN) stimulation in Parkinson's disease. Acta Neurochir (Wien) 2006;148:389-394.

35. Witt K, Pulkowski U, Herzog J, al. Deep brain stimulation of the subthalamic nucleus improves cognitive flexibility but impairs response inhibition in Parkinson disease. Arch Neurol 2004;61:697-700.

36. Brusa L, Pierantozzi M, Peppe A, Altibrandi MG, Giacomini P, Mazzone $P$ et al. Deep brain stimulation (DBS) attentional effects parallel those of I-dopa treatment. J Neural Transm 2001;108:1021-1027.

37. Daniels C, Krack P, Volkmann J, et al. Risk factors for executive dysfunction after subthalamic nucleus stimulation in Parkinson's disease. Mov Disord 2010;25:1583-1589.

38. Mikos A, Zahodne L, Okun MS, Foote K, Bowers D. Cognitive declines after unilateral deep brain stimulation surgery in Parkinson's disease: a controlled study using Reliable Change, part II. Clin Neuropsychol 2010;24:235-245.

39. Fraraccio M, Ptito A, Sadikot A, et al. Absence of cognitive deficits following deep brain stimulation of the subthalamic nucleus for the treatment of Parkinson's disease. Arch Clin Neuropsychol 2008;23:399-408.

40. Dujardin K, Defebvre L, Krystkowiak P, Blond S, Destée A. Influence of chronic bilateral stimulation of the subthalamic nucleus on cognitive function in Parkinson's disease. J Neurol 2001;248:603-611.

41. Jahanshahi M, Ardouin CM, Brown RG, et al. The impact of deep brain stimulation on executive function in Parkinson's disease. Brain 2000; 123:1142-1154.

42. Fields JA, Tröster Al, Wilkinson SB, Pahwa R, Koller WC. Cognitive outcome following staged bilateral pallidal stimulation for the treatment of Parkinson's disease. Clin Neurol Neurosurg 1999;101:182-188.

43. Hershey T, Campbell MC, Videen TO, et al. Mapping Go-No-Go performance within the subthalamic nucleus region. Brain 2010;133:36253634.

44. Rouaud T, Dondaine T, Drapier S, et al. Pallidal stimulation in advanced Parkinson's patients with contraindications for subthalamic stimulation. Mov Disord 2010;25:1839-1846.

45. Mikos A, Pavon J, Bowers D, et al. Factors related to extended hospital stays following deep brain stimulation for Parkinson's disease. Parkinsonism Relat Disord 2010;16:324-328.

46. Denheyer M, Kiss ZH, Haffenden AM. Behavioral effects of subthalamic deep brain stimulation in Parkinson's disease. Neuropsychologia 2009;47:3203-3209.

47. Fimm B, Heber IA, Coenen VA, Fromm C, Noth J, Kronenbuerger M Deep brain stimulation of the subthalamic nucleus improves intrinsic alertness in Parkinson's disease. Mov Disord 2009;24:1613-1620.

48. Lueken U, Schwarz M, Hertel F, Schweiger E, Wittling W. Impaired performance on the Wisconsin Card Sorting Test under left- when compared to right-sided deep brain stimulation of the subthalamic nucleus in patients with Parkinson's disease. J Neurol 2008;255:1940-1948.

49. Alberts JL, Voelcker-Rehage C, Hallahan K, et al. Bilateral subthalamic stimulation impairs cognitive-motor performance in Parkinson's disease patients. Brain 2008;131:3348-3360.

50. Campbell MC, Karimi M, Weaver PM, et al. Neural correlates of STN DBS-induced cognitive variability in Parkinson disease. Neuropsychologia 2008;46:3162-3169 .

51. Page D, Jahanshahi M. Deep brain stimulation of the subthalamic nucleus improves set shifting but does not affect dual task performance in Parkinson's disease. IEEE Trans Neural Syst Rehabil Eng 2007;15: 198-206.

52. Witjas T, Kaphan E, Régis J, et al. Effects of chronic subthalamic stimulation on nonmotor fluctuations in Parkinson's disease. Mov Disord 2007;22:1729-1734.

53. Ory-Magne F, Brefel-Courbon C, Simonetta-Moreau M, Fabre N, Lotterie JA, Chaynes $P$ et al. Does ageing influence deep brain stimulation outcomes in Parkinson's disease? Mov Disord 2007;22:1457-1463.

54. Tir M, Devos D, Blond S, et al. Exhaustive, one-year follow-up of subthalamic nucleus deep brain stimulation in a large, single-center cohort of parkinsonian patients. Neurosurgery 2007;61:297-304.

55. Aybek S, Gronchi-Perrin A, Berney A, et al. Long-term cognitive profile and incidence of dementia after STN-DBS in Parkinson's disease. Mov Disord 2007;22:974-981.
56. Perriol MP, Krystkowiak P, Defebvre L, Blond S, Destée A, Dujardin K. Stimulation of the subthalamic nucleus in Parkinson's disease:cognitive and affective changes are not linked to the motor outcome. Parkinsonism Relat Disord 2006;12:205-210.

57. Schüpbach WM, Chastan N, Welter ML, et al. Stimulation of the subthalamic nucleus in Parkinson's disease:a 5 year follow up. J Neurol Neurosurg Psychiatry 2005;76:1640-1644.

58. Smeding HM, Esselink RA, Schmand B, et al. Unilateral pallidotomy versus bilateral subthalamic nucleus stimulation in PD--a comparison of neuropsychological effects. J Neurol 2005;252:176-182.

59. Lezak MD, Howieson DB, Loring DW, Hannay JH, Fischer JS. Neuropsychological Assessment. New York: Oxford University Press; 2004.

60. Tosi SMVD, Rossetti MO, Rabelo IS. STROOP - Adaptação Brasileira do Teste das Cores e Palavras; 2007.

61. Duncan MT. Obtenção de dados normativos para desempenho no teste de Stroop num grupo de estudantes do ensino fundamental em Niterói. J Bras Psiquiatr 2006;55:42-48.

62. Hamdan AC, Hamdan EMLR. Effects of age and education level on the Trail Making Test in A healthy Brazilian sample. Psychol Neurosc 2009;2:199-203.

63. Nascimento E. Adaptação da terceira edição da escala Wechsler de inteligência para adultos (WAIS-III) para uso no contexto brasileiro. Temas Psicol 1998:6.

64. Randolph C, Mohr E, Chase TN. Assessment of intellectual function in dementing disorders:validity of WAIS-R short forms for patients with Alzheimer's, Huntington's, and Parkinson's disease. J Clin Exp Neuropsychol 1993; 15:743-753

65. Malloy-Diniz LF, Lasmar VAP, Gazinelli LSR, Fuentes S, Salgado JV. The Rey Auditory-Verbal Learning Test:applicability for the Brazilian elderly population. Rev Bras Psiquiatr 2007;29:324-329.

66. Teruya LC, Ortiz KZ, Minett TSC. Performance of normal adults on Rey auditory LlearningTtest:A pilot study. Arq Neuropsiquiatr 2009;67: 224-228.

67. Fichman HC, Dias LBT, Fernandes CS, Lourenço R, Carmelli P, Nitrini R. Normative data and construct validity of the Rey Auditory Verbal Leraning Test in a Brazilian elderly population. Psychol Neurosc 2010;3:79-84.

68. Tombaugh TN, Kozak J, Rees L. Normative data stratified by age and education for two measures of verbal fluency:FAS and animal naming. Arch Clin Neruopsychol 1996;14:167-177

69. Brucki SM, Malheiros SM, Okamoto $\mathrm{H}$, Bertolucci PH. Normative data on the verbal fluency test in the animal category in our milieu. Arq Neuropsiquiatr 1997;55:56-61.

70. Brucki SM, Rocha MS. Category fluency test:effects of age, gender and education on total scores, clustering and switching in Brazilian Portuguese-speaking subjects. Braz J Med Biol Res 2004;37:1771-1777.

71. Miotto EC, Sato J, Lucia MCS, Camargo CHP, Scaff M. Development of an adapted version of the Boston Naming Test for Portuguese speakers. Rev Bras Psiquiatr 2010;32:279-282.

72. Heaton RK, Chelune GJ, Talley JL, Kay GG, Curtiss G. Teste Wisconsin de Classificação de Cartas. São Paulo: Casa do Psicólogo; 2004.

73. Pasquali L, Wechsler S, Bensusan E. Matrizes progressivas do raven infantil: um estudo de validação para o Brasil. Aval Psicol 2002;2:95-110.

74. Castro-Costa E, Fuzikawa C, Uchoa E, Firmo JOA, Lima-Costa MF. Norms for the mini-mental state examination.Arq Neuropsiquiatr 2008; 66:524-528.

75. Brucki SMD, Nitrini R, Caramelli P, Bertolucci PHF, Okamoto IH. Sugestões para o uso do mini-exame do estado mental no Brasil/Suggestions for utilization of the mini-mental state examination in Brazil. Arq Neuropsiquiatr 2003;61:777-781.

76. Laks J, Coutinho ESF, Junger W, et al. Education does not equally influence all the Mini Mental State Examination subscales and items: inferences from a Brazilian community sample. Rev Bras Psiquiatr 2010; 32:223-230.

77. Porto CS, Fichman EC, Caramelli P, Bahia VS, Nitrini R. Brazilian version of the mattis dementia rating scale. Arq Neuropsiquiatr 2003;61: 339-345.

78. Foss MP, Vale FAC, Speciali JG. Influência da escolaridade na avaliação neuropsicológica de idosos: aplicação e análise dos resultados da Escala de Mattis para Avaliação de Demência (Mattis Dementia Rating Scale - MDRS). Arq Neuropsiquiatr 2005;63:119-126.

79. Gorestein C, Andrade L. Validation of a Portuguese version of the Beck Depression Inventory and the State-Trait Anxiety Inventory in Brazilian subjects Braz J Med Biol Res 1996;29:453-457. 
80. Yassuda MS, Flaks MK, Viola LF, et al. Psychometric characteristics of the River mead Behavioural Memory Test (RBMT) as an early detection instrument for dementia and mild cognitive impairment in Brazil. Int Psychogeriatr 2010;22:1003-1111.

81. Mansur LL, Radanovic M, Taquemori L, Greco L, Araújo GC. A study of the abilities in oral language comprehension of the Boston Diagnostic Aphasia Examination Portuguese version: a reference guide for the Brazilian population. Braz J Med Biol Res 2005;38:277-292.

82. Canali F, Brucki SMD, Bertolucci PHF, Bueno OFA. Reliability study of the Behavioral Assessment of the Dysexecutive Syndrome adapted for a Brazilian sample of older- adult controls and probable early Alzheimer's disease patients. Rev Bras Psiquiatr 2011;33:338-346.

83. Beato RG, Nitrini R, Formigoni AP, Caramelli P. Brazilian version of the Frontal Assessment Battery (FAB): Preliminary data on administration to healthy elderly. Dement Neuropsychol 2007;1:59-65.

84. Hoops S, Nazem S, Siderowf AD, et al. Validity of the MoCA and MMSE in the detection of $\mathrm{MCl}$ and dementia in Parkinson disease. Neurology 2009;73:1738-1745.

85. Llebaria G, Pagonabarraga J, Kulisevsky J, et al. Cut-off score of the Mattis Dementia Rating Scale for screening dementia in Parkinson's disease. Mov Disord 2008;23:1546-1550.

86. Montaño MBM, Ramos LR. Validade da versão em português da Clinical Dementia Rating/ Validity of the Portuguese version of Clinical Dementia Rating. Rev Saúde Pública 2005;39:912-917.

87. Brown GG, Rahill AA, Gorell JM, et al. Validity of the Dementia Rating Scale in assessing cognitive function in Parkinson's disease. J Geriatr Psychiatry Neurol 1999;12:180-188.

88. Brito GN, Brito LS, Paumgartten FJ, Lins MF. Lateral preferences in Brazilian adults: an analysis with the Edinburgh Inventory. Cortex 1989; 25:403-415.

89. Visser M, Leentjens AF, Marinus J, Stiggelbout AM, Van Hilten JJ. Reliability and validity of the Beck depression inventory in patients with Parkinson's disease. Mov Disord 2006;21:668-672.

90. Leentjens AF, Verhey FR, Lousberg R, Spitsbergen H, Wilmink FW. The validity of the Hamilton and Montgomery-Asberg depression rating scales as screening and diagnostic tools for depression in Parkinson's disease. Int J Geriatr Psychiatry 2000;15:644-649.

91. Leentjens AFG, Dujardin k, Marsh L, Richard IH, Starkstein SE, Martinez-Martin P. Anxiety rating scales in Parkinson's disease: a validation study of the Hamilton anxiety rating scale, the Beck anxiety inventory, and the hospital anxiety and depression scale. Mov Disord 2011;26: 407-415.

92. Castro MMC, Quarantini L, Batista-Neves S, Kraychete DC, Daltro C, Miranda-Scippa A. Validity of the hospital Anxiety and depression scale in patients with chronic pain. Rev Bras Anestesiol 2006;56:470-477.

93. Shansis F, Berlim MT, Mattevi B, Maldonado G, Izquierdo I, Fleck M. Development of the Portuguese version of the Bech-Rafaels en Mania Rating Scale (BRMaS). Rev Psiquiatr - Rio Gd Sul 2004;26:30-38.

94. Souza RG, Borges V, Silva SMCA, Ferraz HB. Quality of life scale in Parkinson's disease PDQ-39 (Brazilian Portuguese version) to assess patients with and without levodopa motor fluctuation. Arq Neuropsiquiatr 2007;65:787-791.

95. Jenkinson C, Fitzpatrick R, Peto V, Greenhall R, Hyman N. The Parkinson's Disease Questionnaire (PDQ-39): development and validation of a Parkinson's disease summary index score. Age Ageing 1997;26: 353-357.

96. Campos-Sousa IS, Campos-Sousa RN, Ataíde Jr L, Soares MMB, Almeida KJ. Executive dysfunction and motor symptoms in Parkinson's disease. Arq Neuropsiquiatr 2010;68:246-251.

97. Hanna-Pladdy B, Enslein A, Fray M, Gajewski BJ, Pahwa R, Lyons KE. Utility of the NeuroTrax Computerized Battery for Cognitive Screening in Parkinson's Disease:Comparison with the MMSE and the MoCA. Int J Neurosci 2010;120:538-543.

98. Silberman CD, Laks J, Capitão CF, Rodrigues CS, Moreira I, Engelhardt E. Recognizing depression in patients with parkinson's disease: accuracy and specificity of two depression rating scale. Arq Neuropsiquiatr 2006;64:407-411.

99. Schrag A, Barone P, Brown RG, et al. Depression Rating Scales in Parkinson's disease: critique and recommendations. Mov Disord 2007; 22:1077-1092.

\section{APPENDIX A}

\begin{tabular}{|c|c|c|c|c|c|}
\hline Data & Year (1.0) & Title & \multicolumn{3}{|l|}{ Authors/ Journal } \\
\hline Goal & \multicolumn{5}{|c|}{ Cognitive assessment (1.0) } \\
\hline Design methodology & $\begin{array}{l}\text { Original article in } \\
\text { humans }(1.0)\end{array}$ & Meta-analysis (1.0) & Case study $(-1.0)$ & $\begin{array}{l}\text { Literature review } \\
(-1.0)\end{array}$ & $\begin{array}{l}\text { Original article on } \\
\text { animals and/or case } \\
\text { study }(-1.0)\end{array}$ \\
\hline Population & $\begin{array}{l}\text { Individuals with } \\
\text { idiopathic PD (1.0) }\end{array}$ & DBS (1.0) & Uni or bilateral (1.0) & STN or GPi (1.0) & \\
\hline Materials & \multicolumn{5}{|c|}{ At least one cognitive test used in the study (1.0) } \\
\hline Results & \multicolumn{5}{|c|}{ Use of resources and computer models to assess cognition $(-1.0)$} \\
\hline Total & \multicolumn{2}{|c|}{$\begin{array}{l}\text { Presence of cognitive positive or negative } \\
\text { results in the summary }(1.0)\end{array}$} & \multicolumn{3}{|c|}{$\begin{array}{l}\text { The study is expected to attain } 8.0 \text { to be } \\
\text { included in the review }\end{array}$} \\
\hline Repeated & \multicolumn{5}{|c|}{ If article is identical to another in the database then it was considered void } \\
\hline
\end{tabular}

